\title{
RILEM TC 247-DTA round robin test: sulfate resistance, alkali-silica reaction and freeze-thaw resistance of alkali- activated concretes
}

\author{
Frank Winnefeld (i) - Gregor J. G. Gluth (iD) Susan A. Bernal (i) • \\ Maria C. Bignozzi - Lorenza Carabba • Sundararaman Chithiraputhiran • \\ Alireza Dehghan • Sabina Dolenec (1D) Katja Dombrowski-Daube • \\ Ashish Dubey • Vilma Ducman · Yu Jin - Karl Peterson • Dietmar Stephan •
}

John L. Provis (i)

Received: 2 May 2020/Accepted: 21 September 2020/Published online: 11 November 2020

(C) The Author(s) 2020

\begin{abstract}
The RILEM technical committee TC 247-DTA 'Durability Testing of Alkali-Activated Materials' conducted a round robin testing programme to determine the validity of various durability testing methods, originally developed for Portland cement based-concretes, for the assessment of the durability of alkali-activated concretes. The outcomes of the round robin tests evaluating sulfate resistance, alkali-silica
\end{abstract}

This article was prepared within the framework of RILEM TC 247-DTA. The article has been reviewed and approved by all members of the TC.

TC Membership

Chair: John L. Provis, UK

Deputy Chair: Frank Winnefeld, Switzerland

TC Members: Kamel Arbi, Netherlands; P.A. Muhammad Basheer, UK; Susan A. Bernal, UK; Dali Bondar, UK; Lorenza Carabba, Italy; Arnaud Castel, Australia; Maria Chiara Bignozzi, Italy; Anja Buchwald, Netherlands; Huisu Chen, P.R. China; Sundaraman Chithiraputhiran, USA; Francesco Colangelo, Italy; Andrzej Cwirzen, Sweden; Martin Cyr, France; Alireza Dehghan, Canada; Sabina Dolenec, Slovenia; Katja Dombrowski-Daube, Germany; Ashish Dubey, USA; Vilma Ducman, Slovenia; Ana Fernández-Jiménez, Spain; Ellis M. Gartner, France; Gregor J.G. Gluth, Germany; R. Douglas Hooton, Canada; Kazuo Ichimiya, Japan; Elie Kamseu, Cameroon; Lesley S.-C. Ko, USA; Pavlo V. Kryvenko, Ukraine; Yuwei Ma, P.R. China; Isabel Martins, Portugal; Sreejith V. Nanukuttan, UK; Angel Palomo, Spain; Karl Peterson, Canada; Penny Pipilikaki, Netherlands; Francisca Puertas, Spain; Aljoša Šajna, Slovenia; Jay G. Sanjayan, Australia; Caijun Shi, P.R. China; Marios N. Soutsos, UK; Dietmar Stephan, Germany; Arezki Tagnit- reaction (ASR) and freeze-thaw resistance are presented in this contribution. Five different alkaliactivated concretes, based on ground granulated blast furnace slag, fly ash, or metakaolin were investigated. The extent of sulfate damage to concretes based on slag or fly ash seems to be limited when exposed to an $\mathrm{Na}_{2} \mathrm{SO}_{4}$ solution. The mixture based on metakaolin showed an excessive, very early expansion, followed

Hamou, Canada; Monique Tognonvi, Canada; Manuel Torres, Spain; Siska L.A. Valcke, Netherlands; Arie van Riessen, Australia; Jannie S.J. van Deventer, Australia; Jeanette H.M. Visser, Netherlands; Steffen Wache, Germany; Claire E. White, USA; Guang Ye, Netherlands; Yibing Zuo, Netherlands.

Electronic supplementary material The online version of this article (https://doi.org/10.1617/s11527-020-01562-0) contains supplementary material, which is available to authorized users.

F. Winnefeld

Empa, Swiss Federal Laboratories for Materials Science and Technology, Überlandstrasse 129, 8600 Dübendorf, Switzerland

G. J. G. Gluth

Bundesanstalt für Materialforschung und -prüfung (BAM), Unter den Eichen 87, 12205 Berlin, Germany

S. A. Bernal

School of Civil Engineering, The University of Leeds, Leeds LS2 9JT, UK 
by a dimensionally stable period, which cannot be explained at present. In the slag-based concretes, $\mathrm{MgSO}_{4}$ caused more expansion and visual damage than $\mathrm{Na}_{2} \mathrm{SO}_{4}$; however, the expansion limits defined in the respective standards were not exceeded. Both the ASTM C1293 and RILEM AAR-3.1 test methods for the determination of ASR expansion appear to give essentially reliable identification of expansion caused by highly reactive aggregates. Alkali-activated materials in combination with an unreactive or potentially expansive aggregate were in no case seen to cause larger expansions; only the aggregates of known very high reactivity were seen to be problematic. The results of freeze-thaw testing (with/without deicing salts) of alkali-activated concretes suggest an important influence of the curing conditions and experimental conditions on the test outcomes, which need to be understood before the tests can be reliably applied and interpreted.

Keywords Alkali-activated concrete Alkali-silica reaction - Blast furnace slag - Durability testing · Fly ash $\cdot$ Freeze-thaw resistance $\cdot$ Metakaolin $\cdot$ Round robin $\cdot$ Sulfate attack

\section{Introduction}

Alkali-activated concretes have shown sufficient durability to apply them for full-scale application, as demonstrated for

\section{S. A. Bernal · J. L. Provis $(\bowtie)$}

Department of Materials Science and Engineering, University of Sheffield, Sheffield S1 3JD, UK

e-mail: j.provis@sheffield.ac.uk

\section{C. Bignozzi · L. Carabba}

Department of Civil, Chemical, Environmental and Materials Engineering, University of Bologna, Via Terracini 28, 40131 Bologna, Italy

S. Chithiraputhiran - A. Dubey

Corporation Innovation Center, USG Corporation, 700

North Highway 45, Libertyville, IL 60048, USA

A. Dehghan · K. Peterson

Department of Civil and Mineral Engineering, University

of Toronto, 35 St. George Street, Toronto,

ON M5S 1A4, Canada

S. Dolenec · V. Ducman

Slovenian National Building and Civil Engineering Institute (ZAG), Dimičeva ulica 12, 1000 Ljubljana, Slovenia alkali-activated concretes based on ground granulated blast furnace slags [1-3]. However, there are still open questions regarding the long-term durability of alkali-activated materials (AAMs) [4, 5], which are related to the wide range of precursors and activators that can be used. This, in turn, leads to a wide variety in hydrate phase chemistries and microstructural characteristics of these materials. The work of RILEM technical committee (TC) 247-DTA 'Durability Testing of Alkali-Activated Materials' has been targeted to perform a round robin testing programme to assess the validity of different durability testing methods concerning alkali-activated concretes. The two previous papers derived from the activities of RILEM TC 247-DTA presented the outcomes of round robin tests on compressive strength [6] and on carbonation and chloride penetration testing [7]. The TC evaluation of testing methodologies for the determination of sulfate resistance, alkali-silica reaction and freezethaw resistance is highlighted in this contribution.

The underlying mechanisms related to sulfate attack on Portland cement-and blended Portland cement-based concretes are largely well understood; however, there is still a lack of agreement on suitable accelerated laboratory tests of sulfate resistance. For further details the reader is referred to the state-of-the-art report of RILEM TC 211-PAE (Performance of cement-based materials in aggressive aqueous environments) [8]. The sulfate resistance of AAMs was reviewed in the state-of-the-art report of RILEM TC 224-AAM (Alkali-activated materials) [1], and more recently e.g. by Zhang et al. [9], Arbi et al. [10],

\author{
K. Dombrowski-Daube \\ Institute of Mining and Special Civil Engineering, \\ Technische Universität Bergakademie Freiberg, Gustav- \\ Zeuner-Straße 1A, 09599 Freiberg, Germany \\ Y. Jin · D. Stephan \\ Building Materials and Construction Chemistry, \\ Technische Universität Berlin, Gustav-Meyer-Allee 25, \\ 13355 Berlin, Germany
}

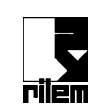


Bernal and Provis [4], and Provis [5]. The interaction of AAMs with sulfates is often tackled in the context of sulfuric acid attack, but a reasonable number of published studies deal also with the interaction of AAMs with $\mathrm{Na}_{2} \mathrm{SO}_{4}$ or $\mathrm{MgSO}_{4}$ solutions. It is generally agreed that according to accelerated laboratory tests the resistance of AAMs to sulfate attack is quite high; however, experience from field tests is very scarce. Fly ash-based AAMs show high sulfate resistance when tested using sodium and magnesium sulfate solutions. Slag-based AAMs generally exhibit a high resistance to $\mathrm{Na}_{2} \mathrm{SO}_{4}$ solutions, while $\mathrm{MgSO}_{4}$ solutions are often deleterious, especially at high concentrations, as decalcification of calcium silicate hydrate $(\mathrm{C}-\mathrm{S}-\mathrm{H})$ and gypsum formation occur, which lead to a loss of dimensional and structural integrity. Information on sulfate resistance of pure metakaolin-based AAMs is scarce in the open literature. According to Hawa et al. [11] these materials exhibit a high volume stability when exposed to $5 \% \mathrm{Na}_{2} \mathrm{SO}_{4}$ and $5 \% \mathrm{MgSO}_{4}$ solutions, respectively, except for a very early expansion during the first week of storage, which was not further explained by the authors.

The question of alkali-silica (or more broadly, alkali-aggregate) reactions in AAMs is contentious in many parts, particularly because AAMs often contain alkalis at levels that are an order of magnitude higher than the levels that are conventionally considered "safe" for Portland cement-based concretes. The science and engineering of alkali-silica reactions in AAMs has been reviewed in detail by Shi et al. [12]. Published results from tests conducted across a variety of AAM binder-aggregate combinations do not indicate that alkali-silica reactions are unduly problematic in AAM concretes or mortars produced using aggregates of 'normal' reactivity [12]. Expansion attributed to alkali-silica reactions can certainly be induced under accelerated conditions, particularly when using an aggregate type known to be reactive [13, 14]. However, in most reported cases of this type, AAM mortars formulated with reactive aggregates have shown less expansion than compared to Portland cement-based mortars produced with the same aggregates, despite the difference in alkali content [13, 15-17]. The binder chemistry of AAMs generally leads to a high $\mathrm{Al}$ concentration in the pore solution and a limited availability of reactive calcium, which is believed to restrict alkali-silica expansion by a mechanism analogous to the action of aluminous pozzolans in concrete with Portland cement blends [13, 16, 18].
Depending on the application, the freeze-thaw resistance, with or without the presence of deicing salts, can be another important aspect of the durability of concrete. Though early publications claimed an "excellent" freeze-thaw resistance for alkali-activated fly ash [19] as well as for alkali-activated slag concrete [20], the parameters influencing freeze-thaw damage of alkali-activated concretes have received little attention-with few exceptions [21-23] — and remain poorly understood to date [5]. To establish such an understanding via comparison of microstructural alterations and concrete performance, it is important to first evaluate the applicability of existing freeze-thaw resistance test methods to alkali-activated concretes.

\section{Materials and methods}

\subsection{Starting materials, concrete mix designs and curing}

Hard coal fly ash (FA), supplied by BauMineral (Germany), ground granulated blast furnace slag (BFS), supplied by ECOCEM ${ }^{\circledR}$ (France), and flashcalcined metakaolin (MK), supplied by Argeco (France) were used as solid precursors. Sodium silicate solutions were used as the activators in each mix, adjusted to the targeted compositions (Table 1) by adding appropriate amounts of water and sodium hydroxide. Each laboratory used locally available aggregates, and thus, their mineralogical compositions and their grading curves differed between laboratories. For more details the reader is referred to the first paper of the TC work [6].

Two concretes based on BFS, two concretes based on FA, and one concrete based on MK were produced and tested. For the concretes based on BFS and FA, one concrete with a 'moderate' performance and one concrete with a 'high' performance, respectively, were designed. The mix designs and the targeted compressive strengths after 28 days are shown in Table 1, and more details are provided in [6].

The concretes were cured for the first 2 days (or until demouldable) in covered or sealed moulds at 20-23 ${ }^{\circ} \mathrm{C}$, and subsequently until the testing age in tightly closed plastic bags at $20-23{ }^{\circ} \mathrm{C}$. For some tests, differing mix designs and curing regimes were applied as described in Sects. 2.2-2.4. 
Table 1 Mix designs $\left(\mathrm{kg} / \mathrm{m}^{3}\right)$ and approximate design strengths of the alkali-activated concretes, reproduced from [6, 7]

\begin{tabular}{|c|c|c|c|c|c|c|c|c|}
\hline Concrete & $\begin{array}{l}\text { Precursor } \\
\left(\mathrm{kg} / \mathrm{m}^{3}\right)\end{array}$ & $\begin{array}{l}\text { Sodium } \\
\text { silicate } \\
\text { dose }^{\mathrm{a}}\end{array}$ & $\begin{array}{l}\text { Sodium } \\
\text { hydroxide } \\
\text { dose }^{b}\end{array}$ & $\begin{array}{l}\text { water/ } \\
\text { binder } \\
\text { mass ratio }^{c}\end{array}$ & Aggregate grading ${ }^{\mathrm{d}}$ & $\begin{array}{l}\text { Design air } \\
\text { content } \\
(\%)^{\mathrm{e}}\end{array}$ & $\begin{array}{l}\text { Design } \\
\text { density } \\
\left(\mathrm{kg} / \mathrm{m}^{3}\right)^{\mathrm{e}}\end{array}$ & $\begin{array}{l}\text { Design } \\
\text { strength } \\
(\mathrm{MPa})\end{array}$ \\
\hline S3a & BFS, 375 & 2.69 & 4 & 0.382 & $\begin{array}{l}40 \% \text { sand } 0-4 \mathrm{~mm}, 60 \% \\
\text { gravel } 4-16 \mathrm{~mm} \text {, to meet } \\
\text { A/B } 16 \text { curve }\end{array}$ & 1.0 & 2375 & 60 \\
\hline $\mathrm{S} 1 \mathrm{~b}$ & BFS, 357 & 1.34 & 3 & 0.420 & $\begin{array}{l}40 \% \text { sand } 0-4 \mathrm{~mm}, 60 \% \\
\text { gravel } 4-16 \mathrm{~mm} \text {, to meet } \\
\text { A/B } 16 \text { curve }\end{array}$ & 1.0 & 2364 & 35 \\
\hline FA2 & FA, 425 & 16.5 & 5.9 & 0.223 & To meet A/B 16 curve & 3.0 & 2350 & 65 \\
\hline FA8 & FA, 425 & 16.5 & 5.9 & 0.253 & To meet A 16 curve & 3.0 & 2324 & 50 \\
\hline MK1 & MK, 350 & 32.3 & 2.7 & 0.393 & To meet $\mathrm{A} / \mathrm{B} 16$ curve & 1.0 & 2186 & 60 \\
\hline
\end{tabular}

${ }^{\mathrm{a}}$ Represented as $\mathrm{g} \mathrm{Na} \mathrm{Si}_{2} \mathrm{O}_{5} / 100 \mathrm{~g}$ precursor, where the solid component of sodium silicate solution of modulus 2.0 is given as $\mathrm{Na}_{2} \mathrm{Si}_{2} \mathrm{O}_{5}$. Where a different modulus of sodium silicate solution was used in some labs, the total activator dose was held constant but the division between silicate and hydroxide constituents was changed

${ }^{\mathrm{b}}$ Represented as $\mathrm{g} \mathrm{NaOH} / 100 \mathrm{~g}$ precursor

${ }^{\mathrm{c}}$ Including water added within the aqueous activator solution, or separately from the activator, and with "binder" defined as the sum of precursor and solid activator components

${ }^{\mathrm{d}}$ Participants were instructed to match the A 16 (coarse) or A/B 16 (between coarse A and fine B) curves of DIN 1045-2 as closely as possible; some labs could only access all-in aggregates or only two different aggregate fractions and this gave some intrinsic variability, whereas others were able to blend multiple fractions to give a closer match to the specified curve

${ }^{\mathrm{e}}$ The air content and density given here are nominal values used in mix design, and will vary depending on the nature of the aggregates, mixing and casting protocols used in each lab

\subsection{Sulfate resistance testing}

As testing methods ASTM C1012 [24], the SVA test [25], and the accelerated test according to Swiss Standard SIA 262/1 Appendix D [26, 27] were selected.

ASTM C1012 [24] is based on expansion measurements of $25 \mathrm{~mm} \times 25 \mathrm{~mm} \times 285 \mathrm{~mm}$ mortar bars stored in a $5 \mathrm{wt} \% \mathrm{Na}_{2} \mathrm{SO}_{4}$ solution at $23{ }^{\circ} \mathrm{C}$ for 12-18 months. The mortar bars are specified to be cured at $35{ }^{\circ} \mathrm{C}$ for the first $24 \mathrm{~h}$, demoulded, and then cured in lime water until a compressive strength of $20 \mathrm{MPa}$ has been reached. This means that quite immature samples are tested when mixes that are intended to develop moderate to high strength at 28 days are being tested. The use of other solutions such as

\footnotetext{
${ }^{1}$ Where dated citations to standards are given in this paper, the reference citation is intended to be referring to a version of the standard that was in force and/or used by the majority of participants at the time of testing, not any updated versions that were released in the intervening time until the paper was finalised and published.
}

$\mathrm{MgSO}_{4}$ is also possible, and this was tested by one participating laboratory.

Pre-curing in saturated lime water is prescribed in ASTM C1012, specifically targeted at improving the maturity of Portland cement-based materials. Nevertheless, it was carried out for the AAMs tested. Although secondary effects such as leaching of the activator, formation of calcium-containing phases in the pore space, and/or formation of gypsum during the later storage in sulfate solution may occur, it was not possible to directly replace this curing condition within the specified procedure of this standard, and it does not appear that any of the potential interfering effects were significantly detrimental to the samples.

The SVA test [25] uses mortar prisms $10 \mathrm{~mm} \times$ $40 \mathrm{~mm} \times 160 \mathrm{~mm}$, which are cured at $20^{\circ} \mathrm{C}$ for 2 days in the mould and subsequently 12 days in saturated lime water. Afterwards a set of samples is stored at $5{ }^{\circ} \mathrm{C}$ and at $20{ }^{\circ} \mathrm{C}$, respectively, in $4.4 \mathrm{wt} \% \mathrm{Na}_{2} \mathrm{SO}_{4}$ solution, while a set of control samples remains in saturated lime water at the same temperatures. Length change and dynamic modulus of elasticity are followed over time. 
Mortar mix designs for the above test methods were developed based on the compositions of the concretes FA2, FA8, S1b and S3a, see Table S1 in the Electronic Supplementary Material, which deviate from the specifications of ASTM C1012 and SVA. For all mortars, the composition of the paste (i.e. solid binder plus activator solution) was identical to the paste composition of the respective concretes. CEN standard sand (EN 196-1 [28]) with a nominal maximum grain size of $2.0 \mathrm{~mm}$ was specified as the aggregate.

While ASTM C1012 and the SVA test are designated to assess the binder, SIA 262/1 Appendix D $[26,27]$ is a method to test the concrete directly. Concrete cores with a diameter of $28 \mathrm{~mm}$ and a length of $150 \mathrm{~mm}$ are drilled out of larger samples cured for 28 days. Afterwards the samples are in contact with sulfate ions during 4 cycles of immersion in $5 \mathrm{wt} \% \mathrm{Na}_{2} \mathrm{SO}_{4}$ solution $\left(5\right.$ days at $20{ }^{\circ} \mathrm{C}$ ) and drying ( 2 days at $50{ }^{\circ} \mathrm{C}$ ). After the 4 th cycle the specimens are immersed again in the sulfate solution, and length and mass changes are measured up to 56 days storage time in $5 \mathrm{wt} \%$ sulfate solution at $20{ }^{\circ} \mathrm{C}$.

\subsection{Alkali-silica reaction testing}

The alkali-silica reaction testing was conducted according to the RILEM AAR-3 method [29], as well as an adapted version of ASTM C1293 [30], which are both based on prismatic concrete samples within the range of dimensions $75( \pm 5) \mathrm{mm} \times 75( \pm 5) \mathrm{mm} \times$ $250( \pm 50) \mathrm{mm}^{2}$ In applying both of these tests, the specified exposure conditions $\left(38^{\circ} \mathrm{C}\right.$ in a sealed storage container; provisions which are near-identical in the two test methods) were followed, but the mix designs described in Table 1 were used unmodified, rather than following the mix designs specified by the standard. Each laboratory used a different alkalireactive aggregate combination, as described in Sect. 4.2. The alkali contents of the mix designs in Table 1 are all significantly higher than the $5.25 \mathrm{~kg} / \mathrm{m}^{3}$ specified in ASTM C1293-08b [30], or the $5.5 \mathrm{~kg} / \mathrm{m}^{3}$ specified in RILEM AAR-3.1 [29]. By testing without adjustment of the concrete alkali content, direct

\footnotetext{
$\overline{2}$ The dimensional tolerances specified in ASTM C1293 are much tighter than the bounds shown here, but fall within the broader range specified for the RILEM AAR-3 method as long as no aggregate particles are larger than $25 \mathrm{~mm}$, as was the case here.
}

application of this test method to alkali-activated concretes may therefore be expected to give a somewhat conservative determination of the alkalireaction potential of the aggregate used.

ASTM C1293 specifies that for measurements of length changes, the samples are to be cooled down to $23{ }^{\circ} \mathrm{C}$ and measured by reference to a zero point taken at $23.5 \pm 0.5 \mathrm{~h}$. The test specifies a criterion of $0.04 \%$ expansion at 12 months to indicate problematic behaviour, whereas if the expansion has not reached $0.04 \%$ at 24 months, the combination of cementitious and aggregate constituents should be able to "prevent excessive expansion in field concretes".

The RILEM AAR-3.1 test method was applied according to the 2011 revision of the testing methodology, as published in the State of the Art Report of RILEM TC 219-ACS [29]. This test specifies a measurement temperature of $20^{\circ} \mathrm{C}$, referenced to a zero point that is defined at $24 \pm 1 \mathrm{~h}$.

The test specification document for the AAR-3.1 method does not set explicit pass/fail criteria, but the results of the EU PARTNER project [31] indicate that a 12-month expansion of less than $0.05 \%$ in this test is "likely to indicate non-expansive materials", while an expansion of $0.1 \%$ or more indicates an expansive combination, and results between 0.05 and $0.1 \%$ show a potential for alkali-reactivity.

\subsection{Freeze-thaw resistance testing}

Freeze-thaw resistance testing methods included the CDF test [32] as well as the tests according to ASTM C666 (Procedure A) [33] and ASTM C672 [34]. Neither air-entraining agents nor any other compounds or measures were used to adapt the concretes to freeze-thaw attack. The CDF test and the test according to ASTM C672 involve the use of deicing salt, while the test according to ASTM C666 uses water only. For conventional concretes, the former two test methods are thought to cause deterioration mainly in the near-surface regions, while attack without deicing salts affects the inner regions as well [35].

The CDF test consists of exposing a minimum of five concrete specimens with dimensions $150 \mathrm{~mm} \times$ $150 \mathrm{~mm} \times(50-150) \mathrm{mm}$ to freeze-thaw cycles while partially immersed in a $3 \% \mathrm{NaCl}$ aqueous solution. Curing and pre-treatment of the specimens is prescribed as follows: Curing in the moulds at $20 \pm 2{ }^{\circ} \mathrm{C}$ for $24 \mathrm{~h}$; demoulding and curing in tap 
water at $20 \pm 2{ }^{\circ} \mathrm{C}$ for six days; dry storage at $20{ }^{\circ} \mathrm{C} /$ $65 \%$ relative humidity (RH) for 21 days, during which the lateral surfaces of the specimens are sealed; presaturation by partially immersing the specimens in the test solution $(3 \mathrm{wt} \% \mathrm{NaCl})$ at $20{ }^{\circ} \mathrm{C}$ for seven days. Each freeze-thaw cycle of the CDF test has a duration of $12 \mathrm{~h}$, during which the temperature is lowered from $20 \pm 1{ }^{\circ} \mathrm{C}$ to $-20 \pm 1{ }^{\circ} \mathrm{C}$, held at that temperature for $3 \mathrm{~h}$, increased back to $20 \pm 1{ }^{\circ} \mathrm{C}$ and then held at this temperature for $1 \mathrm{~h}$. At specified intervals, the surface scaling of the immersed surface is determined through ultrasonic treatment to remove loosely adhering material, which is then dried and weighed. Assessment of the resistance of a concrete is usually based on the cumulative surface scaling after 28 freeze-thaw cycles; a common acceptance criterion is that the surface scaling is $\leq 1500 \mathrm{~g} / \mathrm{m}^{2}$ after 28 cycles [36].

In the present testing campaign, curing conditions differed between laboratories: Laboratory B followed the instructions of the CDF test entirely; in laboratory $\mathrm{A}$, the initial curing up to seven days was done in sealed conditions at $23{ }^{\circ} \mathrm{C}$ to avoid leaching of activator components, after which dry storage was conducted as prescribed; and curing in laboratory $\mathrm{C}$ was done at $\sim 20{ }^{\circ} \mathrm{C}$ in a closed box over an open water surface for 28 days, and immediately thereafter pre-saturation by immersion in the test solution was started (i.e. no dry storage was conducted). Laboratory A reported that, for some of the tested concretes, the specimen surfaces to be immersed were ground to flatness within the dry storage period, because their visual appearance in terms of smoothness and efflorescence was unsatisfactory. The same laboratory tested a second set of concrete specimens which were cured in sealed conditions at $23{ }^{\circ} \mathrm{C}$ for 56 days (instead of seven days) before dry storage; all other pre-treatment steps were completed as prescribed.

Laboratory D performed the tests according to ASTM C666 (Procedure A) and ASTM C672. For the test according to ASTM C672, concrete slabs with dimensions $220 \mathrm{~mm} \times 220 \mathrm{~mm} \times 76.2 \mathrm{~mm}$ were produced, with the flat surfaces of the slabs covered by $6 \mathrm{~mm}$ of either $4 \mathrm{wt} \% \mathrm{CaCl}_{2}$ aqueous solution or $4 \mathrm{wt} \% \mathrm{NaCl}$ aqueous solution and then exposed to 90 freeze-thaw cycles $\left(16 \mathrm{~h}\right.$ at $-20{ }^{\circ} \mathrm{C}$ then $8 \mathrm{~h}$ at $25^{\circ} \mathrm{C}$ ); the test solution was replaced each five cycles. At specified intervals, the surfaces were visually examined and qualitatively rated according to the scale given in ASTM C672; in addition, the mass change of the specimens was determined and reported.

The ASTM C666 test procedure was modified for the application to AAM concretes through a change in curing conditions. Instead of limewater saturation, concrete specimens $(76.2 \mathrm{~mm} \times 101.6 \mathrm{~mm} \times 406.4$ $\mathrm{mm}$ ) were removed from the moulds after $24 \mathrm{~h}$, then air cured until the age of 28 days, and subsequently submerged in water for 14 days. Test procedure A consists of exposing the specimens, while submerged in water, to up to 300 freeze-thaw cycles $\left(4{ }^{\circ} \mathrm{C}\right.$ to $-18{ }^{\circ} \mathrm{C}$ within two to five hours). At regular intervals, the absolute and relative dynamic moduli of elasticity were recorded.

\section{Reporting of results}

Pre-formatted templates were used by the round robin participants for reporting of the test results and to register deviations from the standard procedures as described in Sects. 2 and 4.

Five laboratories reported sulfate resistance testing data, three laboratories reported alkali-silica reaction testing data, and four laboratories reported freezethaw resistance data.

All results are given, summarised as the laboratories' mean values with their standard deviations, in the Electronic Supplementary Material (Tables S1-S12) accompanying this article. In Sect. 4, these results are graphically presented and discussed.

\section{Results and discussion}

\subsection{Sulfate resistance testing}

Due to the limited number of participants in the sulfate resistance part of the round robin test, a full interlaboratory assessment of the results is not possible. Thus, the discussion of the results is focussed on the comparison between the different methods.

\subsubsection{ASTM C1012}

The mix design of the AAM tested was different from the mix design specified in ASTM C1012, as described in Sect. 2.2 and shown in Table S1 in the Electronic Supplementary Material. 
(a)

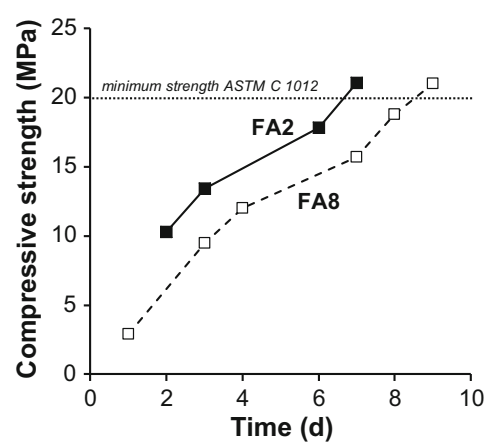

(b)

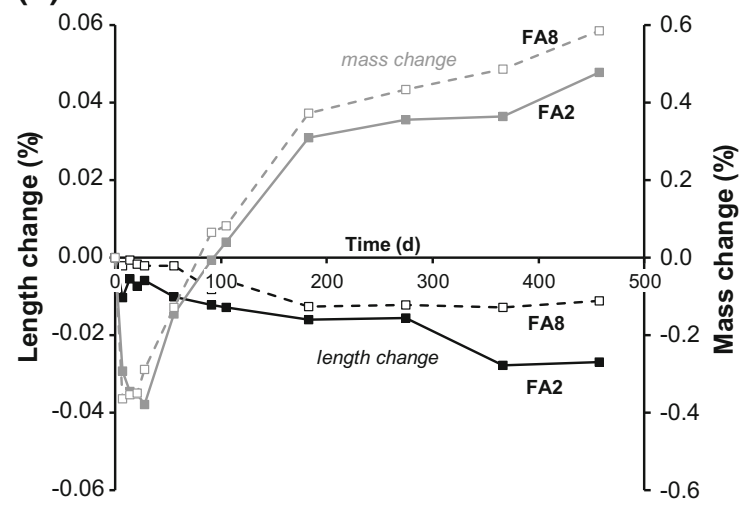

Fig. 1 Sulfate resistance of fly ash-based AAM mortar mixes tested according to ASTM C1012; a Compressive strength development for maturity assessment, b Length and mass changes in $5 \mathrm{wt} \% \mathrm{Na}_{2} \mathrm{SO}_{4}$. Results of Laboratory $\mathrm{E}$

Figure 1a shows the compressive strength development of the fly ash-based mortars during storage in saturated lime water, as reported by laboratory E. Both mixes show a steady development of compressive strength. Mix FA2 reaches the $20 \mathrm{MPa}$ threshold specified in ASTM C1012 for the start of exposure testing after $7 \mathrm{~d}$, and mix FA8 after $9 \mathrm{~d}$ of curing.

Figure $1 \mathrm{~b}$ gives length and mass changes of the fly ash-based AAM mixes stored in $5 \mathrm{wt} \% \mathrm{Na}_{2} \mathrm{SO}_{4}$. Neither mix shows any expansion, but a slight shrinkage instead. During the first 3-4 weeks of storage, a mass loss from the samples occurs, probably due to the leaching of the activator. Afterwards a continuous mass increase occurs, which does not seem to have stabilized after 15 months of exposure.

Figure 2 compares the ASTM C1012 length changes for all five mixes based on slag, fly ash or metakaolin, measured by one of the participating laboratories. The results for the fly ash mixes compare well with the data shown in Fig. 1b, although a different initial curing regime was used ( 2 days at $20{ }^{\circ} \mathrm{C}$ in the mould, instead of 2 days at $35^{\circ} \mathrm{C}$ ). The slag-based AAM mixes show a negligible change (S1b) or slight expansion (S3a) after one year of storage in $\mathrm{Na}_{2} \mathrm{SO}_{4}$. It can be speculated whether the differences between both slag samples are significant, and if the higher expansion of the higher performance slag mix S3a compared to the moderate one (S1b) is due to its higher binder content. Another participating laboratory found the reverse rank order for $\mathrm{S} 1 \mathrm{~b}$ and $\mathrm{S} 3 \mathrm{a}$ under $\mathrm{Na}_{2} \mathrm{SO}_{4}$ exposure (Fig. 3), with small
Fig. 2 Length changes of all AAM mortars tested in $5 \mathrm{wt} \% \mathrm{Na}_{2} \mathrm{SO}_{4}$ according to ASTM C1012. Note that pre-curing in the mould was done at $20{ }^{\circ} \mathrm{C}$ for $48 \mathrm{~h}$ (instead of $24 \mathrm{~h}$ at $35^{\circ} \mathrm{C}$ ). Compressive strengths after pre-curing were: FA8: 19.5 MPa (13 d), FA2: 22.0 MPa (16 d), S3a: $20.6 \mathrm{MPa}$ (3 d), S1b: 22.0 MPa (6 d), MK: 54.1 MPa (2 d). Results of Laboratory $\mathrm{H}$

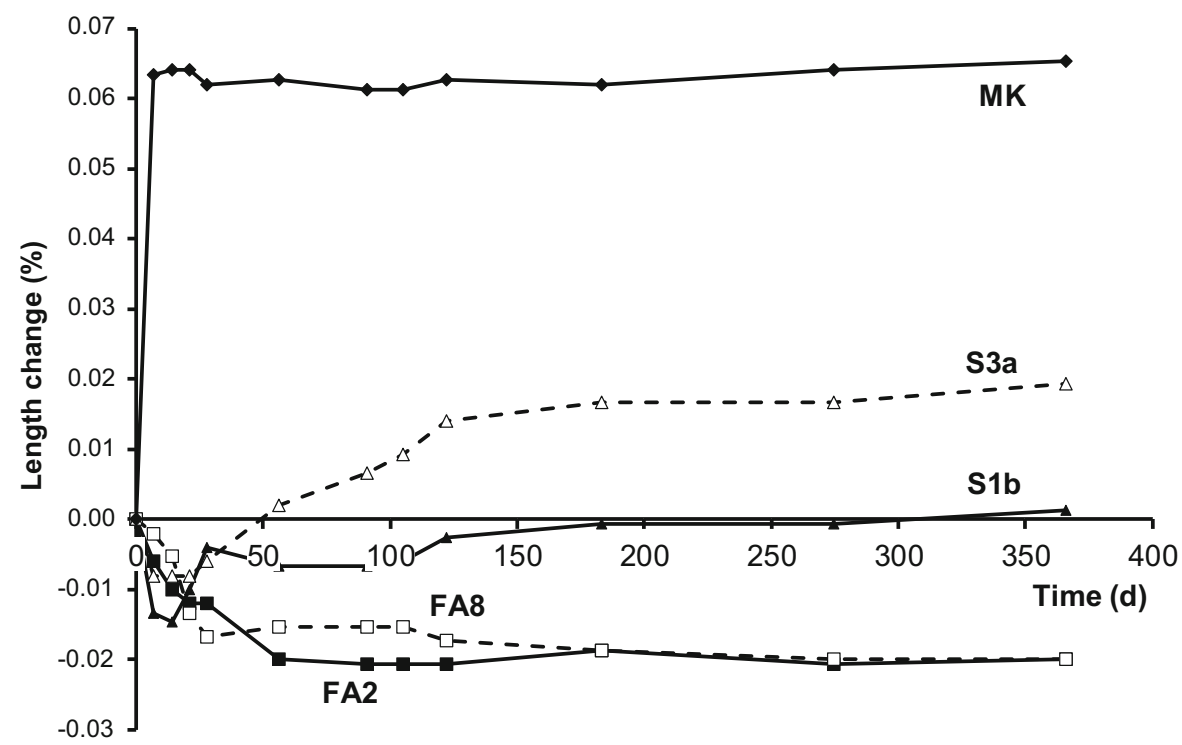




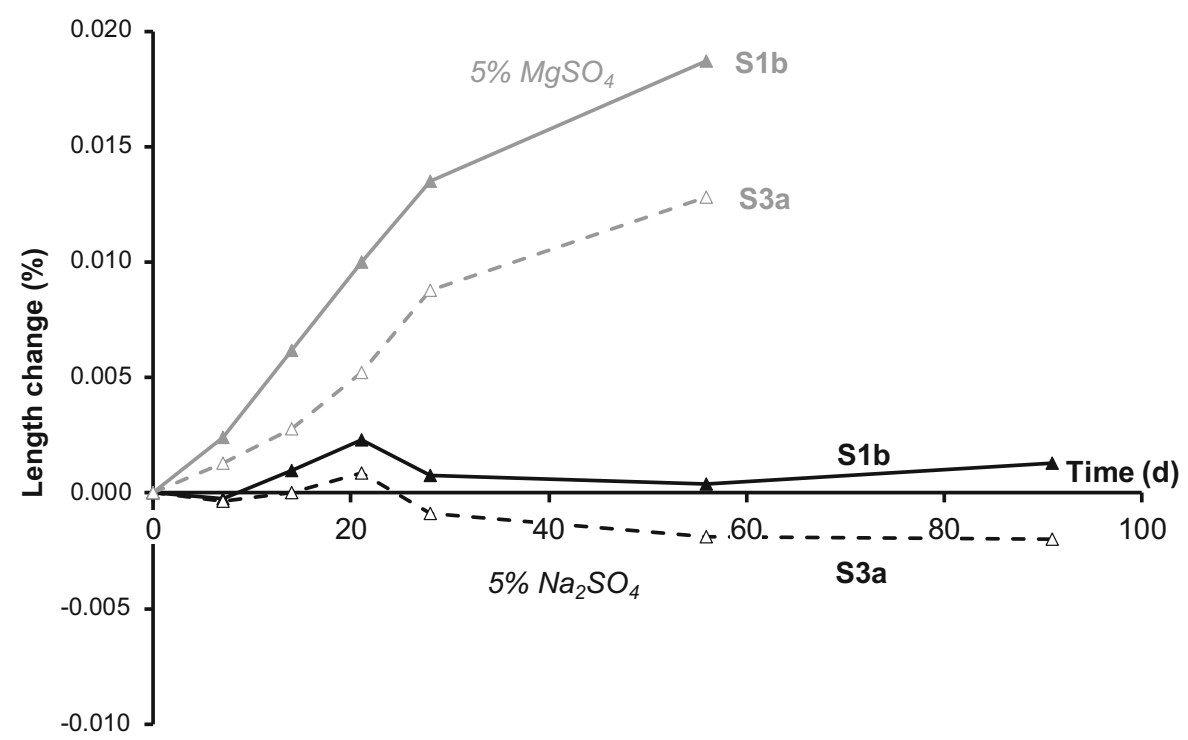

Fig. 3 Length changes of slag-based AAM mortars tested in $5 \mathrm{wt} \% \mathrm{Na}_{2} \mathrm{SO}_{4}$ and in $5 \mathrm{wt} \% \mathrm{MgSO}_{4}$ according to ASTM C1012. Samples were submerged in sulfate solution after $24 \mathrm{~h}$ of pre-curing in the mould at $35^{\circ} \mathrm{C}$. Compressive strengths after pre-curing were: S3a: 16.1 MPa (1 d), S1b: 22.7 MPa (1 d). S3a

expansion in S1b and actually a minor contraction in S3a. However, there were no significant dimensional stability issues in any of these cases; expansions and contractions measured for the fly ash-based and slagbased AAMs were all well within the specified "safe" limits (generally $0.1 \%$ ).

Surprisingly, the MK mix in Fig. 2 shows a fast and early expansion after 7 days of storage, while afterwards no significant length changes occur. This behaviour is in agreement with the findings of Hawa et al. [11], however due to its rapid onset and shortterm nature it is unlikely to be linked to any conventional sulfate attack mechanisms, and it is beyond the scope of the present paper to provide further detailed discussion proposing an underlying expansion mechanism. However, this observation highlights the importance of taking multiple length measurements (not solely a final measurement after several weeks or months) when seeking information about the nature of expansive processes in AAMs. This finding also raises discussion about the appropriate time to determine and define the "zero point" for measurements such as this, and also the alkalisilica reaction tests described in Sect. 4.2. It has to be further noted that the MK mix already showed a very high compressive strength of over $50 \mathrm{MPa}$ before was tested also after 1 additional day of curing in saturated lime water, where a compressive strength of $22.0 \mathrm{MPa}$ was reached, and the results (not shown) did not differ significantly from the results with $24 \mathrm{~h}$ of pre-curing. Results of Laboratory F

starting the immersion, which significantly exceeds the minimum strength of $20 \mathrm{MPa}$ as required by ASTM C1012.

As calcium-containing binder systems (e.g. blended with Portland cement or alkali-activated slag) are often attacked by $\mathrm{MgSO}_{4}$ solutions more severely than by $\mathrm{Na}_{2} \mathrm{SO}_{4}$ solutions [37], one participant carried out the $\mathrm{C} 1012$ test using both solutions (Fig. 3). With $\mathrm{Na}_{2} \mathrm{SO}_{4}$ no expansion is measured, while the rank order between $\mathrm{S} 1 \mathrm{~b}$ and $\mathrm{S} 3 \mathrm{a}$ is reversed compared to the data shown in Fig. 2. Conversely, the samples stored in $\mathrm{MgSO}_{4}$ solution show a slight expansion. The moderate-strength mix S1b expands slightly more than the higher-strength mix S3a. While the samples stored in $\mathrm{Na}_{2} \mathrm{SO}_{4}$ did not show any visually recognisable damage on the surfaces, the specimens stored in the $\mathrm{MgSO}_{4}$ solution were evidently corroded at the corners and the edges.

The expansion limit of $0.1 \%$ as specified in ASTM C595 for blended Portland cements [37] at 12 months in $\mathrm{Na}_{2} \mathrm{SO}_{4}$ for high sulfate resistance is not exceeded by any of the samples tested here according to ASTM C1012, neither in $\mathrm{Na}_{2} \mathrm{SO}_{4}$ nor in $\mathrm{MgSO}_{4}$. 


\subsubsection{SVA test}

For the SVA test [25], mortars were used as well, and their mix design is shown in Table S1 in the Electronic Supplementary Material. The testing was performed by one participating laboratory, and on the slag-based mixes (S1b and S3a) only. Length changes in $4.4 \mathrm{wt} \%$ $\mathrm{Na}_{2} \mathrm{SO}_{4}$ and in saturated lime solution (reference) were measured at $20{ }^{\circ} \mathrm{C}$ up to 91 days. Measurements at $5{ }^{\circ} \mathrm{C}$ were not carried out. It is noted that length change measurements in saturated lime solutions might not be an appropriate zero-point reference for AAMs, but this curing method is specified by the test method, and was therefore implemented.

While the samples stored in saturated lime solution showed neither significant shrinkage nor expansion, the samples stored in $\mathrm{Na}_{2} \mathrm{SO}_{4}$ solution exhibited very limited shrinkage, in the order of $0.003 \%$ (Table S4). The maximum expansion limit for high sulfate resistance is specified in this test to be a difference between length changes in $\mathrm{Na}_{2} \mathrm{SO}_{4}$ and saturated lime solution of $0.05 \%$ after $90 \mathrm{~d}$, so the observed expansion falls well within this limit. Mass changes were negligible for both slag mixes under both exposure conditions (Table S4).

\subsubsection{SIA 262/1 Appendix D}

One participant used a modified version of SIA 262/1 Appendix D [26, 27] to test the resistance of the slag- and fly ash-based mixtures to $\mathrm{MgSO}_{4}$ attack. Four $50 \mathrm{~mm} \times 50 \mathrm{~mm} \times 285 \mathrm{~mm}$ concrete prisms were used (instead of six $\varnothing 20 \mathrm{~mm} \times 150 \mathrm{~mm}$ drilled cores as specified in the testing method documents). Instead of $5 \mathrm{wt} \% \mathrm{Na}_{2} \mathrm{SO}_{4}, 5 \mathrm{wt} \% \mathrm{MgSO}_{4}$ solution was used. The samples were stored for up to two years after the initial four loading sulfate cycles. In parallel, a separate set of replicate samples was stored according to the conditions described in ASTM C1012, but after pre-curing for 28 days. In this case, the $\mathrm{MgSO}_{4}$ solution was exchanged after each measurement of length and mass.

The length changes determined according to the modified SIA 262/1 Appendix D method are shown in Fig. 4. While the fly ash-based mixes do not show a significant expansion, the slag-based mixes reach values of $0.061 \%(\mathrm{~S} 1 \mathrm{~b})$ and $0.068 \%(\mathrm{~S} 3 \mathrm{a})$, respectively. Those values are below the limit of $0.1 \%$ specified for a sulfate resistant cement. The slag-based concrete prisms showed some minor cracking at the edges, while the fly ash-based mixtures showed no signs of physical damage. When using the modified ASTM C1012 (Table S5), severe scaling of the surface of the slag-based concretes was observed, while the expansion was less $(0.018 \%$ for S1b and $0.028 \%$ for S3a) than for the SIA method. For the fly ash-based concretes only a negligible expansion was measured, and no signs of physical damage occurred.

Both the modified versions of the SIA and the ASTM methods used larger specimens than specified
Fig. 4 Length changes of fly ash- and slagbased AAM concrete prisms in $5 \mathrm{wt} \% \mathrm{MgSO}_{4}$ using the modified SIA 262/1 Appendix D method. Results of Laboratory $\mathrm{G}$

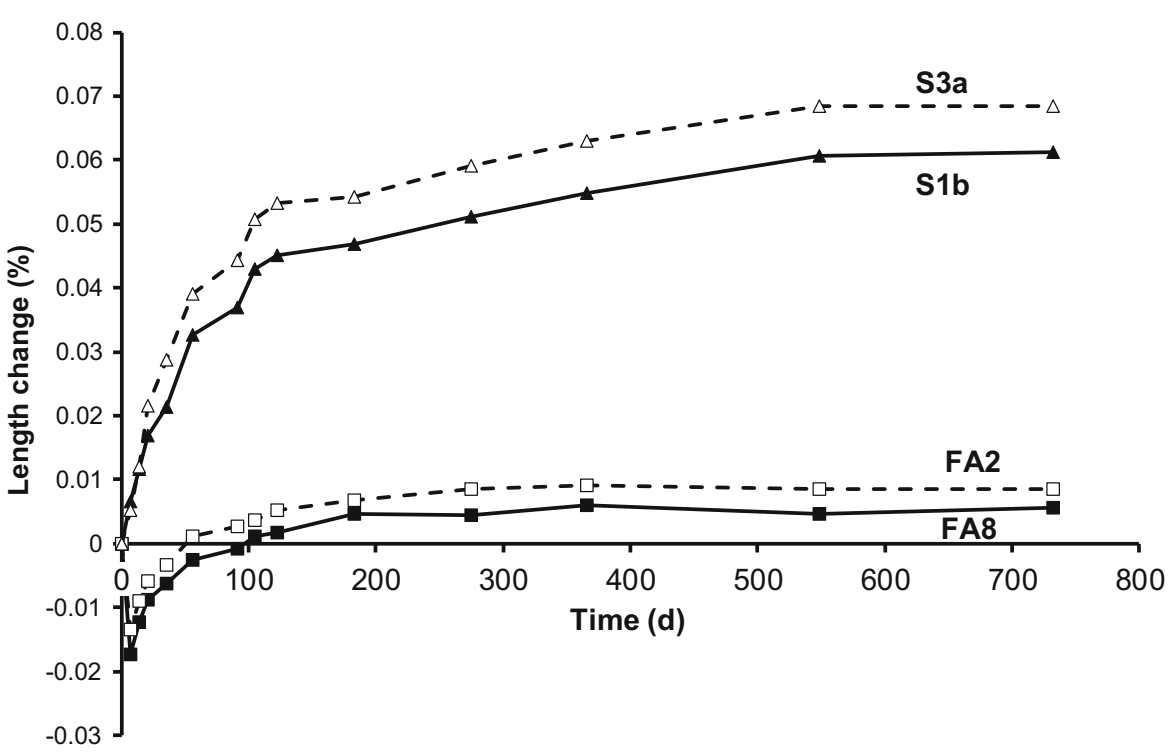


in the respective standards, and thus it could be possible that expansion was restricted by a limited penetration depth of sulfate compared to the diameter of the specimens. By micro-X-ray fluorescence analyses $(\mu-X R F)$ it has been shown that significant ingress of sulfate occurred for a slag-based AAM concrete tested according to the ASTM method, while this was not the case in the SIA setup [38]. For the fly ash mixes, both testing methods produced similar concentration gradients over the depths of the specimens.

\subsection{Alkali-silica reaction testing}

Laboratories $\mathrm{G}, \mathrm{H}$, and I reported the results of alkalisilica reaction testing: Laboratory G used the ASTM C1293 [30] method, adapted as described in Sect. 2.3, while Laboratories $\mathrm{H}$ and I applied the RILEM AAR3.1 [29] test. All of these tests are applied to concrete prism specimens; the $\mathrm{C} 1293$ and AAR-3.1 tests are conducted at $38{ }^{\circ} \mathrm{C}$, and Laboratory I also conducted a parallel test with exposure at $20^{\circ} \mathrm{C}$ but otherwise following the RILEM AAR-3.1 methodology.

The RILEM AAR-3.1 test also specifies that mass change measurements should be taken at each interval to ensure that there has not been drying of the samples; any mass loss from conventional cements is taken to indicate insufficient availability of water and leads to results being discarded [29]. Laboratory I (which tested only mix FA8 with different aggregates) observed an initial mass gain of $3-5 \%$ for all specimens at the first measurement point then little change $(<0.3 \%$ variation in any specimen) thereafter, while Laboratory $\mathrm{H}$ recorded mass decreases of $\sim 1.5 \%$ for the FA8 and MK samples, $0.3 \%$ for FA2, and negligible change for S1b. Although the ASTM C1293 method applied in Laboratory G does not specifically require the measurement of mass changes, this information was nonetheless recorded; all samples gained up to $0.9 \%$ mass during the 24 months of testing, without a clear trend regarding whether the mass change occurred early or late for each particular specimen. The mass change data recorded in each laboratory are provided in the Electronic Supplementary Material. Due to the uncertainty around whether this provision of the test method is relevant for testing of AAMs, data corresponding to samples with mass losses were not discarded from this study.
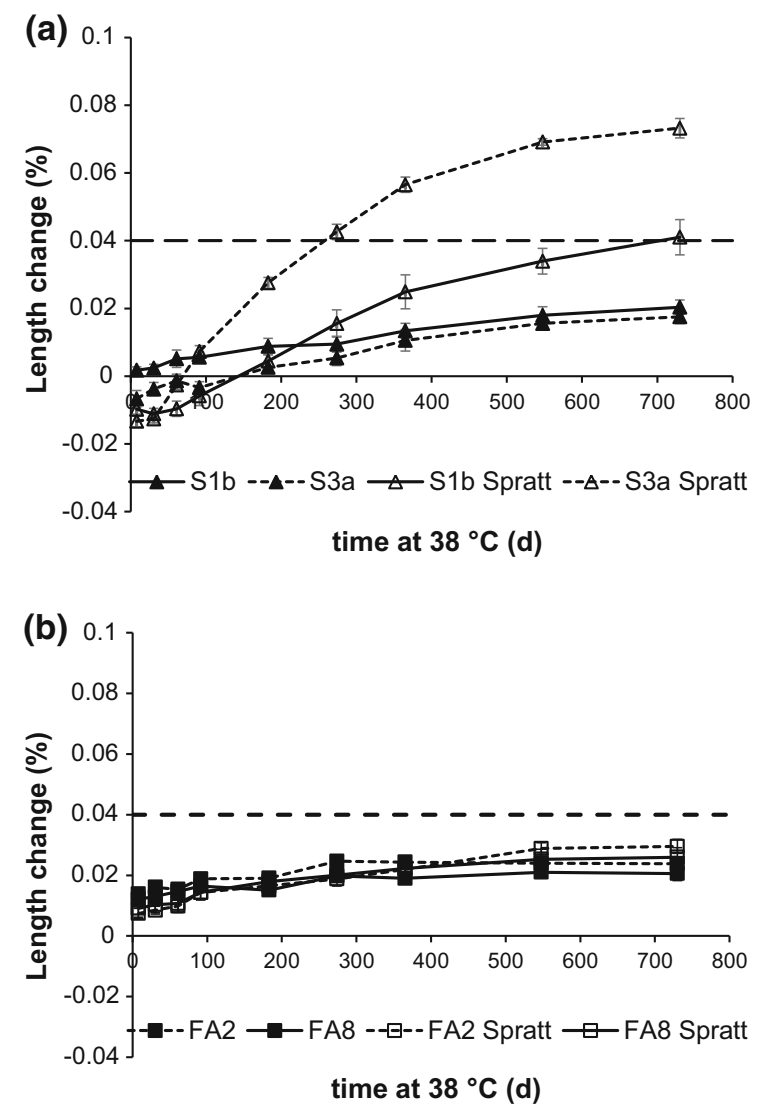

Fig. 5 ASTM C1293 results from Laboratory G. a slag-based samples, b fly ash-based samples. Error bars represent one standard deviation among 4-6 replicate samples, and where not visible are smaller than the data symbols

Figure 5 shows the data recorded in Laboratory $\mathrm{G}$ using ASTM C1293, where concretes were tested both with conventional aggregates, and also with replacement of the coarse aggregates by highly reactive Spratt limestone (sourced from Ontario, Canada), which is known to cause expansive reactions in conventional cement concretes [39]. The results obtained using the Spratt aggregates in slag-based AAM binders (Fig. 5a) show that the test method is suitable for the detection of cases where excessive expansion would be expected, as both slag-based AAMs exceeded the $0.04 \%$ expansion limit after 2 years with this type of aggregate. However, when using aggregates that were not expected to be problematically reactive when used with Portland cements, the expansions observed at 2 years for S1b and S3a were approximately half the specified limit, even with a concrete alkali content 
vastly exceeding the design alkali content for concretes specified to be used in this testing method.

None of the fly ash-based AAMs (Fig. 5b) exceeded the specified expansion limit after 2 years, even when the Spratt aggregate was used. Approximately half of the total observed expansion took place very early in the testing, within the first week. It is very unlikely that such early expansion is related to alkaliaggregate reaction processes, as these are generally much slower to develop, and this raises potentially important questions about the setting of the length reference datum (i.e., the point taken as zero expansion) for this test when applied to alkali-activated materials. This will be revisited below in the discussion of further results for fly ash-based AAM concretes.

A detailed mechanistic analysis of the reasons for the alkali-aggregate reaction behaviour of AAMs is beyond the scope of the current paper, which is instead focused on understanding whether the given test methods are suitable to be applied to AAMs. It is hypothesised that the high $\mathrm{Al}$ content and often low $\mathrm{Ca}$ content of alkali-activated binders are important in controlling alkali-related expansive behaviour, as was discussed in Sect. 1.

The results from Laboratory $G$ indicate that: (a) problematic aggregate-binder combinations (e.g. Spratt in slag-based AAM) can be identified; and (b) that the role of the binder chemistry in influencing aggregate-derived expansion can also be determined (as the Spratt aggregates gave a passing result when tested with a fly ash-based AAM, but failed with a slag-based AAM). These two observations indicate that the ASTM C1293 method can be considered broadly suitable for testing of AAM concretes, although it is evident that comparison between laboratory and long-term field data is still needed to enable a firm conclusion to be drawn regarding the precision of the test method in predicting field performance. The within-laboratory reproducibility of this test appears to be very good; the coefficients of variation among 4-6 replicate prisms at 720 days were less than $12.7 \%$ in all cases (shown as error bars in Fig. 5), and between $10.4-12.7 \%$ in 5 of the 8 data sets collected. This compares remarkably well with the $12 \%$ withinlaboratory coefficient of variation quoted in the ASTM C1293 method specification for expansions of $0.02 \%$ or more [30]. ASTM C1293 quotes a standard deviation of $0.0025 \%$ for length changes less than
$0.02 \%$ [30], compared to $0.0019 \%$ for the results presented here (calculated as the mean of the standard deviation values for all measured length changes not exceeding $0.02 \%$ at any age for any sample). This appears to reflect the intrinsic variability in the manual determination of small length changes, and the standard deviation is not material-specific. The reproducibility of ASTM C1293 therefore appears to be very similar whether it is applied to AAMs or to conventional cement concretes.

The testing programme of RILEM TC 247-DTA did not yield sufficiently large data sets to enable an evaluation of the inter-laboratory reproducibility beyond the statements present in the ASTM C1293 test method documentation.

Figure 6 presents the results from the RILEM AAR-3.1 test (Fig. 6a, b), along with the outcomes of a parallel test conducted in one laboratory where the same test protocol was followed but with exposure at $20{ }^{\circ} \mathrm{C}$ rather than $38^{\circ} \mathrm{C}$ (Fig. 6c). In this laboratory, Laboratory I, tests were conducted using the fly ashand slag-based AAM concretes with a conventional siliceous (river gravel) aggregate and similar petrography for both fine and coarse fractions. In each concrete, a part of one of the aggregate size fractions was replaced by a potentially reactive component: either $58.9 \%$ replacement of fine aggregates by a suspected reactive sand, or $35.9 \%$ replacement of coarse aggregates by Dry Rigg greywacke (a known reactive coarse aggregate [40]).

Figure 6a shows that shrinkage of both fly ashbased AAM mixes took place during the RILEM AAR-3.1 test, while S1b and MK1 expanded less than $0.04 \%$. For FA2, only two of the three prisms shrank, while the third remained dimensionally stable, and this explains the relatively larger error bars shown for this data set. Such variation was not reflected in differences in mass loss between the specimens during the test, so is unlikely to be a drying shrinkage effect. As was observed for the slag-based mixes in the ASTM C1293 results, around half of the total observed expansion of S1b took place during the earliest part (first four weeks) of the test. This supports the discussion presented above, regarding whether this is actually likely to be an ASR-related expansion. It is unlikely that an ASR reaction would be so rapid, and this behaviour is more realistically attributed to other chemical and/or physical changes in the concrete during the first few weeks of its hardening. 

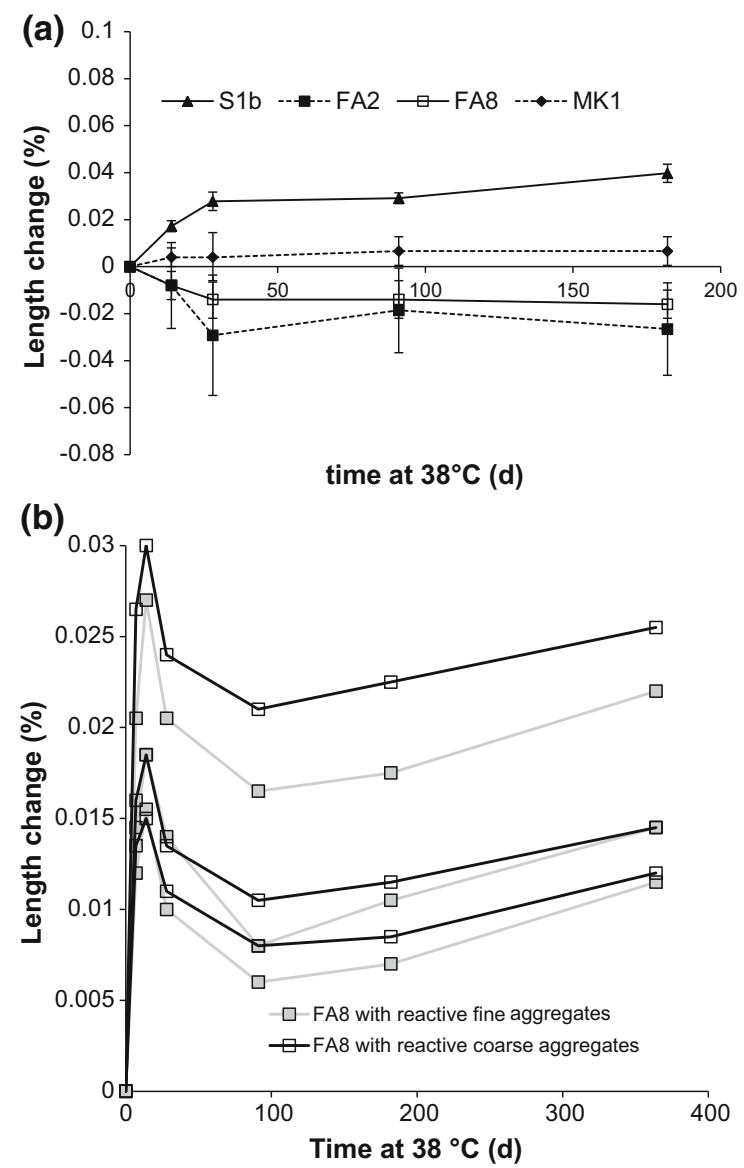

(c)

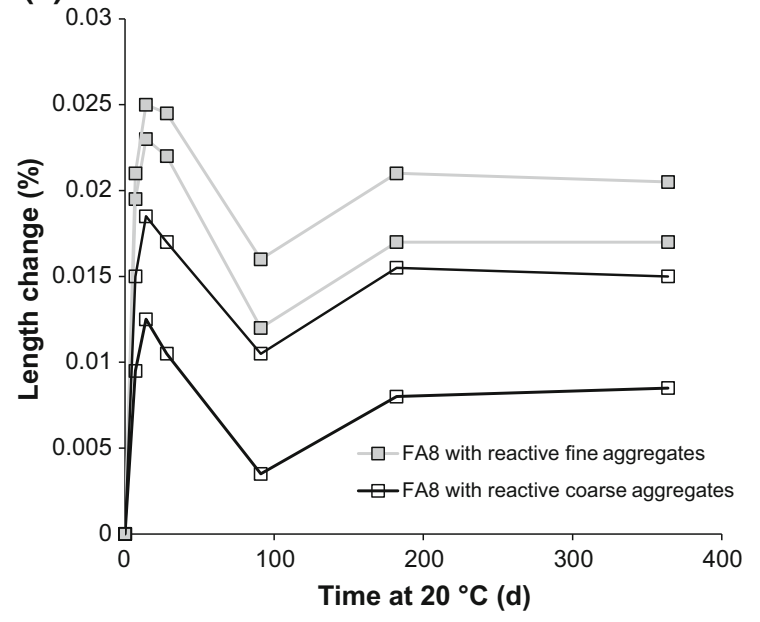

Fig. 6 RILEM AAR-3.1 results from a Laboratory $\mathrm{H}$, b Laboratory I ( $38{ }^{\circ} \mathrm{C}$ results). Parallel $20{ }^{\circ} \mathrm{C}$ test results from Laboratory I are shown in (c). In a, error bars indicate the standard deviation among 2-3 replicate samples. In b and c, replicates of the same test are shown separately, but with the same line and marker styles
Figure $6 \mathrm{~b}$ shows the data from three replicate tests of FA8 in Laboratory I, with either part of the fine aggregates or part of the coarse aggregates replaced by potentially reactive components as noted above. The RILEM AAR-3.1 test specification identifies that the within-laboratory reproducibility should be approximately half of the measured expansion value [29], and for each set of prisms here, the measured results do fall within a range of approximately 50\% above and below the mean for the triplicate samples. Similarly, for the duplicate samples tested at $20{ }^{\circ} \mathrm{C}$ (Fig. 6c), the withinlaboratory variation is approximately $50 \%$ above or below the mean. The measured expansions are all less than $0.03 \%$, and therefore are not considered problematic under the indications of this test method. This indicates that the FA8 concrete mix does not cause undue expansion when using either of these potentially reactive aggregates. It is not possible to use Fig. 6 to conduct a meaningful inter-laboratory comparison of the test results, because Fig. 6a shows only results for unreactive aggregates, while Fig. 6b, c have reactive aggregates included in the mixes.

However, it is striking that in Fig. 6b, c, almost all of the observed length changes take place within the first week of the test. Re-normalising the test results shown in Fig. $6 \mathrm{~b}$ to use the 1-week test result as the effective zero length change datum (i.e. subtracting the 1-week expansion reading from all measured data) yields a very different view of the test outcomes, as seen in Fig. 7. In this re-evaluation of the test data, it is seen that all samples are highly dimensionally stable from the 7th day onwards, without evidence of undue expansion. Nevertheless, all samples do show a slight contraction from 14 to 91 days, then an expansion back to reach the 1-week length again at 360 days. The reproducibility of the re-normalised results is very high, with all of the 360-day data points for the triplicate specimens containing the potentially reactive fine aggregates falling within a range of $0.003 \%$ in length change (range -0.001 to $+0.002 \%$ ), while the triplicate specimens containing the reactive coarse aggregate are all within $0.001 \%$ of each other (range -0.002 to $-0.001 \%$ ).

The RILEM AAR-3.1 test method specification states that "the lowest result for a reactive aggregate should exceed $0.075 \%$ " [29]. On this basis, it can be concluded that none of the combinations tested here with this method can be classified as ASR-reactive, even without the re-normalisation shown in Fig. 7 and regardless of 
Fig. 7 RILEM AAR-3.1 data from Laboratory I (as in Fig. 6b), re-normalised to use the 1-week measurement as the zero length change datum

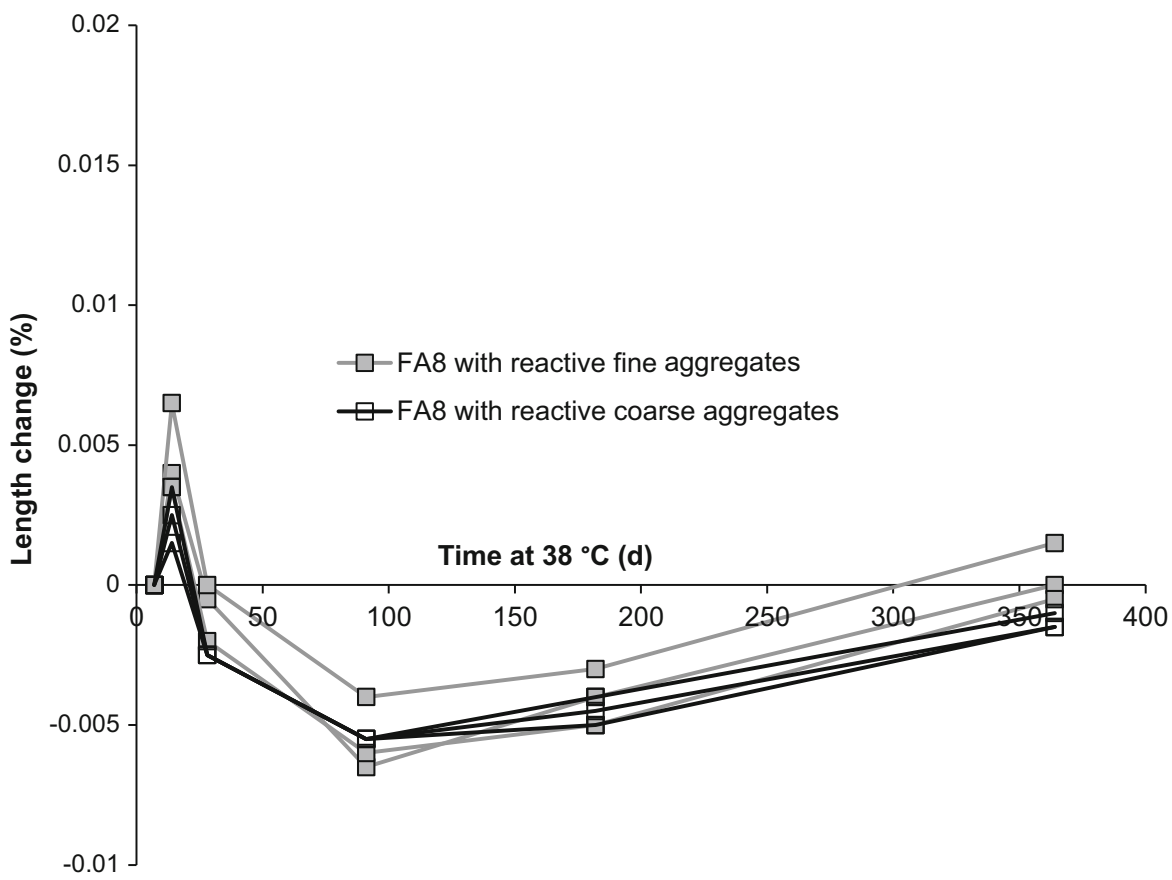

whether potentially reactive aggregates are used. It is not possible to conclusively say from these results whether the RILEM AAR-3.1 test method can actually identify a problematically reactive aggregate-binder combination in AAM concretes, because with no combinations the failure criterion for the test was approached. However, considering the very close similarities between this test and the ASTM C1293 methodology (which is stated in [29] to have been taken into account in the development of the RILEM method), it is likely that the conclusions drawn above for the ASTM method are also applicable to the RILEM method. This method therefore seems to be broadly suitable for the testing of AAM concretes. However, it is recommended that the 1-week measurement be used as the zero length datum point when this type of expansion testing method is applied to AAM concretes. This appears to be the age at which some degree of early-age dimensional stability is achieved, and from which it is possible to identify actual ASR-related processes (which take place at a later age).

\subsection{Freeze-thaw resistance testing}

\subsubsection{CDF test}

The CDF test results of Laboratories A, B and C are shown in Fig. 8. In all cases, the ranking of the performance of the concretes in each laboratory was in the expected order, i.e. for both the slag-based concretes and the fly ash-based concretes, the highstrength mix always exhibited less surface scaling than the moderate-strength mix. Also in line with expectations, MK1, which had the highest water/binder ratio of the low-Ca AAM-based concretes, already exhibited considerably more surface scaling than FA8 after four freeze-thaw cycles. However, while both slagbased concretes exhibited considerably less surface scaling than both of the fly ash-based concretes when tested in Laboratory B, there was no clear distinction between these two groups of concretes in Laboratory A, at least at early test times up to 14 freeze-thaw cycles.

The results of the CDF test differed significantly between laboratories in two further respects. First, the absolute values of surface scaling were very different for the same concrete tested in different laboratories; e.g., after four freeze-thaw cycles FA8 exhibited $3152 \mathrm{~g} / \mathrm{m}^{2}$ of scaled material in Laboratory A, $1973 \mathrm{~g} /$ $\mathrm{m}^{2}$ of scaled material in laboratory B, and $3871 \mathrm{~g} / \mathrm{m}^{2}$ of scaled material in Laboratory C. It can also be noted that concrete $\mathrm{S} 3 \mathrm{a}$ conformed to the acceptance criterion of $\leq 1500 \mathrm{~g} / \mathrm{m}^{2}$ surface scaling after 28 freezethaw cycles in laboratory $\mathrm{B}$, while the same concrete 
Fig. 8 Results of CDF tests obtained in a) Laboratory A, 28-day cured concretes; b) Laboratory A, 56-day cured concretes; c) Laboratory B, 28-day cured concretes; and d) Laboratory C, 28-day cured concretes. Details of all curing conditions are given in Sect. 2.4. Error bars represent one standard deviation in each direction from the mean, within the results recorded by each laboratory
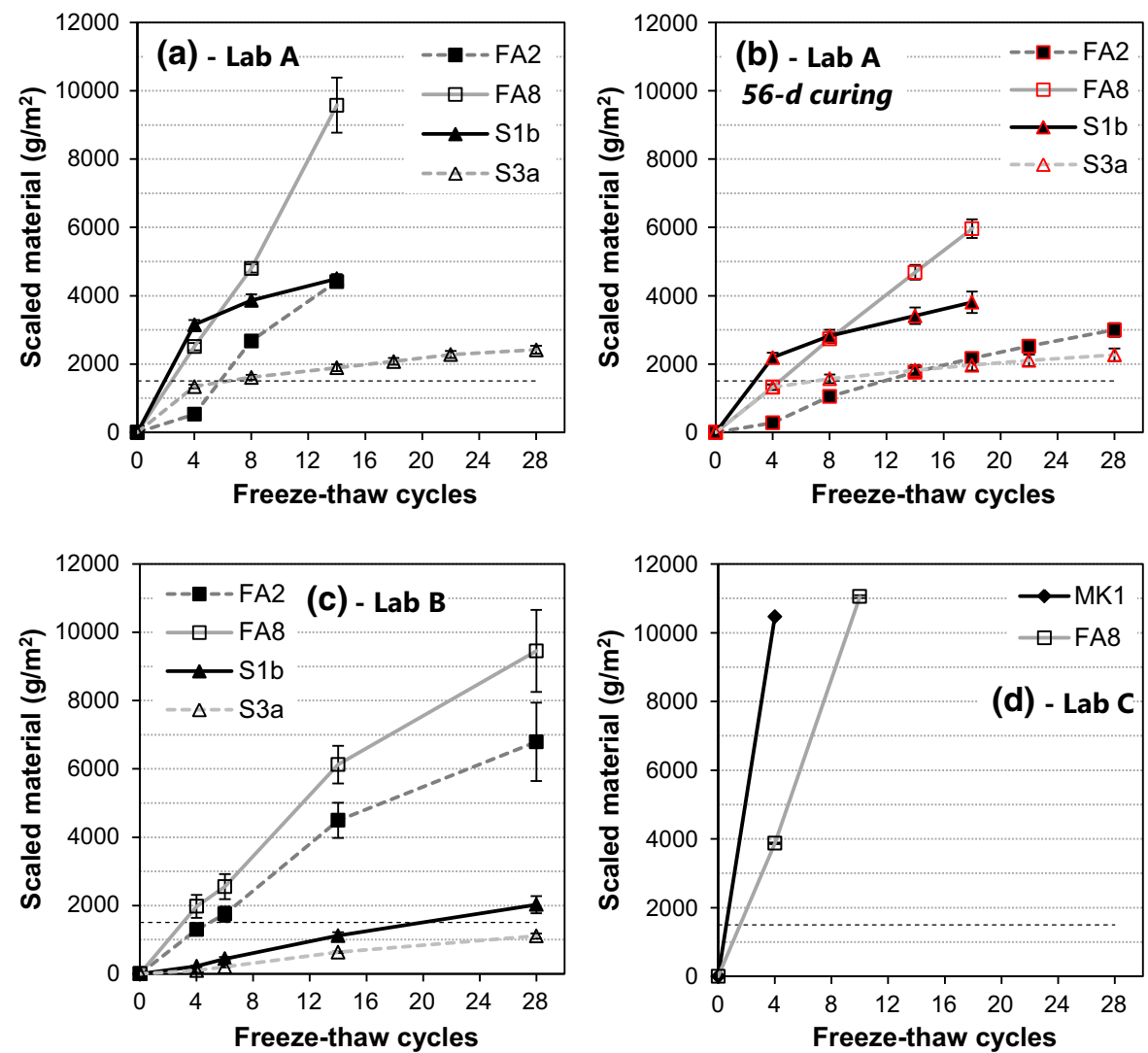

exceeded this limit already after eight freeze-thaw cycles in Laboratory A.

Secondly, and perhaps more important, the shape of the cumulative surface scaling curves of the slagbased concretes differed between laboratories: The results from Laboratory A exhibited a steep increase of the scaled material from zero to four freeze-thaw cycles and a much more moderate increase of cumulative surface scaling at later times, almost plateauing towards the end of the test for S3a (Fig. 8a, b). Conversely, the results from Laboratory B showed an approximately constant slope throughout the test duration for both slag-based concretes (Fig. 8c).

Behaviour corresponding to the results for the slagbased concretes tested in Laboratory A has previously been reported for concretes based on blended Portland cements with $\geq 50 \%$ blast furnace slag. It was found that for these concretes, the depth at which the slope of the cumulative surface scaling curve decreased, coincided with the depth of carbonation (due to exposure to $\mathrm{CO}_{2}$ during curing and dry storage) [35]. The authors of that study assigned this behaviour partly to coarsening of the microstructure of slag-rich cements during carbonation, and in addition contended that transformation of well-crystallized aragonite and vaterite to poorly crystalline $\mathrm{CaCO}_{3}$ during freezethaw attack plays a role as well. For the results of the present testing campaign it is possible that 7-days underwater curing in Laboratory B had led to a more refined microstructure and much less carbonation of the slag-based concrete specimens before freeze-thaw attack than the 7-days sealed-curing in Laboratory A, and that this is the reason for the different results in these laboratories. However, this hypothesis remains to be proven, and it is possible that alkali leaching during immersed curing is also influential on some aspects of the mechanisms for the AAMs described here.

As concretes, particularly with SCM-rich binders, are generally more susceptible to carbonation at an early age [41], an extended curing period before dry storage would be expected to increase the freeze-thaw resistance by decreasing the depth of carbonation 
before freeze-thaw attack, if the above mechanism is operative. Comparing the results for concretes cured in sealed conditions either for 7 days or for 56 days before dry storage and tested under otherwise identical conditions, it is seen that extended sealed-curing did indeed decrease surface scaling of all tested concretes. However, the improvement in resistance caused by extended curing was only minor to moderate for the slag-based concretes (particularly for S3a; Fig. 8a, b). Thus, it remains uncertain whether carbonation is the main factor influencing freeze-thaw resistance of these concretes, and why the shape of their cumulative surface scaling curves differed so strikingly between Laboratory A and Laboratory B. Further work is evidently needed to fully understand the influence of curing on the freeze-thaw test results obtained for AAMs.

\subsubsection{ASTM C666 and ASTM C672}

Laboratory D tested the slag-based concretes S1b and S3a according to the method described in ASTM C672, using either $4 \mathrm{wt} \% \mathrm{CaCl}_{2}$ solution or $4 \mathrm{wt} \%$ $\mathrm{NaCl}$ solution as the test solution. With $\mathrm{CaCl}_{2}, \mathrm{~S} 3 \mathrm{a}$ performed slightly better than $\mathrm{S} 1 \mathrm{~b}$, in line with the results of the CDF test (Sect. 4.3.1), while testing with $\mathrm{NaCl}$ yielded very similar results for $\mathrm{S} 1 \mathrm{~b}$ and $\mathrm{S} 3 \mathrm{a}$ in terms of visual appearance of the surfaces and mass loss (Tables S10 and S11 in the Electronic Supplementary Material). In most cases, "moderate to severe scaling" was observed for both concretes after 90 freeze-thaw cycles.

The test according to ASTM C666 showed a better performance for S3a than for S1b, with the relative dynamic modulus of elasticity after 300 freeze-thaw cycles being $96 \%$ for $\mathrm{S} 3 \mathrm{a}$ and $87 \%$ for S1b (Table S12 in the Electronic Supplementary Material), again in accord with the results of the CDF test as well as testing according to ASTM C672 with $\mathrm{CaCl}_{2}$. These results are, however, not necessarily a confirmation of the CDF and ASTM C672 test results, as testing in the absence of deicing salts causes different damage mechanisms in the concrete compared to testing with $\mathrm{NaCl}$ or $\mathrm{CaCl}_{2}$ solution, potentially including differences in crystallisation pressure during freezing [35], although this remains to be proven for AAMs which can have intrinsically high ionic strengths in their pore fluids even without additional salt application.

\section{Conclusions}

The extent of sulfate damage incurred by AAMs based on slag or fly ash, whether measured by expansion, mass change or visual inspection, seems to be limited. Due to the low expansion values it is difficult to distinguish between the high and the moderate performing mixtures. All three methods used gave similar information and thus seem to be useful to assess sulfate resistance of AAMs based on slag or fly ash. The mixture based on metakaolin showed an excessive, very early expansion, followed by a dimensionally stable period, when tested according to ASTM C1012 exposing the specimens to $\mathrm{Na}_{2} \mathrm{SO}_{4}$. This behaviour was previously described in literature [11] and might need to be assessed in the future. In the slag-based concretes, exposure to $\mathrm{MgSO}_{4}$ caused more expansion and visual damage than $\mathrm{Na}_{2} \mathrm{SO}_{4}$, however the expansion limits defined in the respective standards were not exceeded. The strength limit of $20 \mathrm{MPa}$ set in ASTM C1012 appears to be rather low as quite immature samples are tested.

Both test methods applied for determination of ASR expansion-the ASTM C1293 and RILEM AAR-3.1 methods-appear to provide essentially reliable identification of expansion due to highly reactive aggregates in AAM. The combination of an AAM binder (regardless of precursor) with a nonreactive or potentially-expansive aggregate did not cause problematic expansion in any case. Only the aggregates of known very high reactivity proved to be problematic when combined with AAM binders. It is necessary to carefully consider the selection of the zero expansion datum point for ASR testing of AAM concretes, as there is some initial expansion in these concretes that is unlikely to be linked to a conventional ASR mechanism. There is also a need to validate test results by comparison with field data, as the acceleration of the testing by heating to $38{ }^{\circ} \mathrm{C}$ has not yet been fully justified by comparison with field data obtained over decades or longer, and it may be necessary to more carefully specify pass/fail criteria for this specific type of concrete. Testing at $20{ }^{\circ} \mathrm{C}$ does not seem to bring any particular advantages over a $38{ }^{\circ} \mathrm{C}$ test, and the results obtained at these two temperatures do appear to be correlated closely.

The CDF (freeze-thaw resistance in the presence of $\mathrm{NaCl}$ ) test yielded the same relative performance of the high-strength mixes and the moderate-strength 
mixes in the three participating laboratories. Apart from that, the results from these laboratories differed considerably in terms of absolute values of surface scaling and the relative performance of two classes of concretes (i.e. fly ash-based vs. slag-based), and indicated that curing conditions significantly affect the test results. Testing of the two slag-based concretes according to ASTM C672 was more equivocal, yielding a relative performance that depended on the deicing salt. When tested according to ASTM C666i.e. without deicing salt- these concretes performed in the expected rank order. These results highlight the important influence of the experimental conditionsincluding curing of the specimens-on the outcomes of freeze-thaw resistance tests of alkali-activated concretes. These influences need to be better understood before the tests can be applied with confidence.

Acknowledgements The authors would like to thank all members of RILEM TC 247-DTA for the valuable discussions in planning the activities for the round robin. Particularly we would like to acknowledge the immense contribution of A. Buchwald (ASCEM, Netherlands), W. Rickard and A. van Riessen (Curtin University, Australia), G. Gluth (BAM, Germany), R. Pouhet and M. Cyr (Toulouse University, France) in developing the concrete mix designs evaluated; and for arranging the donations of raw materials, and the logistics for their distribution to all the round robin participants. The participation of Dr Andrew Dunster (BRE, United Kingdom) in the round-robin testing and enriching the associated discussions is very gratefully acknowledged. Dali Bondar (Queens University Belfast, United Kingdom) and Isabel Martins (LNEC, Portugal) are acknowledged for their contributions to the manuscript. We greatly appreciate the help of colleagues, laboratory assistants and students in the participating laboratories, including B. Maier and D. Wend (BAM). Special thanks are also due to Ecocem (France), BauMineral (Germany) and Argeco (France) for the generous donation of several tonnes of slag, fly ash and flash-calcined metakaolin to the members of this technical committee; and to PQ Corporation and Grupo IQE for the donation of activator constituents to some of the participating laboratories.

Funding The participation of J. L. Provis and S. A. Bernal in this research was sponsored by the Engineering and Physical Sciences Research Council (EPSRC; UK) under grant number EP/M003272/1. Participation of V. Ducman and S. Dolenec was financially supported by the Slovenian Research Agency Programme Group P2-0273.

\section{Compliance with ethical standards}

Conflicts of interest The authors declare they have no competing financial interests.
Open Access This article is licensed under a Creative Commons Attribution 4.0 International License, which permits use, sharing, adaptation, distribution and reproduction in any medium or format, as long as you give appropriate credit to the original author(s) and the source, provide a link to the Creative Commons licence, and indicate if changes were made. The images or other third party material in this article are included in the article's Creative Commons licence, unless indicated otherwise in a credit line to the material. If material is not included in the article's Creative Commons licence and your intended use is not permitted by statutory regulation or exceeds the permitted use, you will need to obtain permission directly from the copyright holder. To view a copy of this licence, visit http://creativecommons.org/licenses/by/4.0/.

\section{References}

1. Provis JL, van Deventer JSJ (eds) (2014) Alkali-Activated Materials: State-of-the-Art Report, RILEM TC 224-AAM. Springer/RILEM, Dordrecht

2. Xu H, Provis JL, van Deventer JSJ, Krivenko PV (2008) Characterization of aged slag concretes. ACI Mater J 105(2):131-139

3. Buchwald A, Vanooteghem M, Gruyaert E, Hilbig H, De Belie N (1950s) Purdocement: application of alkali-activated slag cement in Belgium in the 1950s. Mater Struct 48(1-2):501-511

4. Bernal SA, Provis JL (2014) Durability of alkali-activated materials: progress and perspectives. J Am Ceram Soc 97(4):997-1008

5. Provis JL (2018) Alkali-activated materials. Cem Concr Res 114:40-48

6. Provis JL, Arbi K, Bernal SA, Bondar D, Buchwald A, Castel A, Chithiraputhiran S, Cyr M, Dehghan A, Dombrowski-Daube K, Dubey A, Ducman V, Gluth GJG, Nanukuttan S, Peterson K, Puertas F, van Riessen A, TorresCarrasco M, Ye G, Zuo YB (2019) RILEM TC 247-DTA round robin test: mix design and reproducibility of compressive strength of alkali-activated concretes. Mater Struct 52(5):99

7. Gluth GJG, Arbi K, Bernal SA, Castel A, Chithiraputhiran S, Dehghan A, Dombrowski-Daube K, Dubey A, Ducman V, Dunster A, Peterson K, Valcke SLA, Ye G, Zuo YB, Provis JL (2020) RILEM TC 247-DTA round robin test: carbonation and chloride penetration testing of alkali-activated concretes. Mater Struct 53:21

8. Alexander M, Bertron A, De Belie N (eds) (2013) Performance of cement-based materials in aggressive aqueous environments: state-of-the-Art report, RILEM TC 211-PAE. Springer/RILEM, Dordrecht

9. Zhang J, Shi CJ, Zhang ZH, Ou ZH (2017) Durability of alkali-activated materials in aggressive environments: a review on recent studies. Constr Build Mater 152:598-613

10. Arbi K, Nedeljkovic M, Zuo YB, Ye G (2016) A review on the durability of alkali-activated fly ash/slag systems: advances, issues, and perspectives. Ind Eng Chem Res 55(19):5439-5453 
11. Hawa A, Tonnayopas D, Prachasaree W, Taneerananon P (2013) Investigating the effects of oil palm ash in metakaolin based geopolymer. Ceram-Silik 57(4):319-327

12. Shi C, Hu ZSX, Zhao R, Chong L (2015) A review on alkaliaggregate reactions in alkali-activated mortars/ concretes made with alkali-reactive aggregates. Mater Struct 48(3):621-628

13. Pouhet R, Cyr M (2015) Alkali-silica reaction in metakaolin-based geopolymer mortar. Mater Struct 48(3):571-583

14. Tänzer R, Jin Y, Stephan D (2017) Effect of the inherent alkalis of alkali activated slag on the risk of alkali silica reaction. Cem Concr Res 98:82-90

15. Shi Z, Zhao CSR, Wan S (2015) Comparison of alkali-silica reactions in alkali-activated slag and Portland cement mortars. Mater Struct 48(3):743-751

16. Williamson T, Juenger MCG (2016) The role of activating solution concentration on alkali-silica reaction in alkaliactivated fly ash concrete. Cem Concr Res 83:124-130

17. Shi Z, Shi C, Zhang J, Wan S, Zhang Z, Ou Z (2018) Alkalisilica reaction in waterglass-activated slag mortars incorporating fly ash and metakaolin. Cem Concr Res 108:10-19

18. Shi Z, Shi C, Wan S, Ou Z (2017) Effect of alkali dosage on alkali-silica reaction in sodium hydroxide activated slag mortars. Constr Build Mater 143:16-23

19. Škvára F, Jílek T, Kopecký L (2005) Geopolymer materials based on fly ash. Ceram-Silik 49(3):195-204

20. Talling B, Brandstetr J (1989) Present state and future of alkali-activated slag concretes. In: Malhotra VM (ed), Proceedings of the third CANMET/ACI conference on fly ash, slag, silica fume and natural pozzolans in concrete, Trondheim, Norway, vol 2. pp 1519-1545

21. Dombrowski K, Weil M, Buchwald A (2008) Geopolymer binders. Part 2: development and optimization of geopolymer concrete mixtures for strong and durable external walls. ZKG Int 61(3):70-80

22. Fu YW, Cai LC, Wu YG (2011) Freeze-thaw cycle test and damage mechanics models of alkali-activated slag concrete. Constr Build Mater 25(7):3144-3148

23. Dombrowski-Daube K, Sachl J (2019) Durability of alkaliactivated concrete mixtures - a requirement for success in the market. In: Serdar M, Štirmer N, Provis JL (eds) Proceedings of the international conference on sustainable materials, systems and structures (SMSS2019) - new generation of construction materials (RILEM PRO128), Rovinj, Croatia, 20-22 March 2019. RILEM Publications SARL, pp 141-149

24. ASTM International (2018) Standard test method for length change of hydraulic-cement mortars exposed to a sulfate solution (ASTM C1012 / C1012M-18b). West Conshohocken, PA

25. Deutsches Institut für Bautechnik (DIBt) (2012) Testing cement CEM III/A for high sulphate resistance. Berlin, Germany (in German)

26. Swiss Society of Engineers and Architects (SIA) (2013) Betonbau-Ergänzende Festlegungen (Concrete structuressupplementary specifications) (SIA 262/1). Zürich, Switzerland (in German)

27. Loser R, Leemann A (2015) An accelerated sulfate resistance test for concrete. Mater Struct 49(8):3445-3457
28. European Committee for Standardization (2005) Methods of Testing Cement-Part 1: determination of strength (EN 196-1). Belgium, Brussels

29. Nixon PJ, Sims I (2016) RILEM recommendations for the prevention of damage by alkali-aggregate reactions in new concrete structures: State-of-the-art report of the RILEM Technical Committee 219-ACS. Springer/RILEM, Dordrecht

30. ASTM International (2008) Standard Test method for determination of length change of concrete due to alkalisilica reaction (ASTM C1293-08b). West Conshohocken, PA

31. Lindgård J, Nixon PJ, Borchers I, Schouenborg B, Wigum BJ, Haugen M, Akesson U (2010) The EU "PARTNER" Project-European standard tests to prevent alkali reactions in aggregates: final results and recommendations. Cem Concr Res 40(4):611-635

32. Setzer MJ, Fagerlund G, Janssen DJ (1996) CDF test-test method for the freeze-thaw resistance of concrete-tests with sodium chloride solution (CDF). Mater Struct 29(193):523-528

33. ASTM International (2008) Standard test method for resistance of concrete to rapid freezing and thawing (ASTM C666 / C666M-03). West Conshohocken, PA

34. ASTM International (1998) Standard test method for scaling resistance of concrete surfaces exposed to deicing chemicals (ASTM C672 / C672M-98). West Conshohocken, PA

35. Stark J, Wicht B (2013) Dauerhaftigkeit von Beton. Springer Vieweg, Berlin, Germany, pp 438-444 (in German)

36. Bundesanstalt für Wasserbau (2012) BAW-Merkblatt Frostprüfung von Beton (MFB), Ausgabe 2012. Karlsruhe, Germany (in German)

37. Neville A (2004) The confused world of sulfate attack on concrete. Cem Concr Res 34(8):1275-1296

38. Dehghan Najmabadi A (2018) Durability testing protocols for concrete made with alternative binders and recycled materials. $\mathrm{PhD}$ thesis, University of Toronto, Canada:available at https://tspace.library.utoronto.ca/ handle/1807/89790

39. Roger C, Grattan-Bellew PE, Hooton RD, Ryell J, Thomas MDA (2000) Alkali-aggregate reactions in Ontario. Can J Civ Eng 27:246-260

40. Sibbick RG (1993) The susceptibility of various UK aggregates to alkali silica reaction. $\mathrm{PhD}$ thesis, The University of Aston in Birmingham, UK:available at https:// research.aston.ac.uk/en/studentTheses/the-susceptibilityof-various-uk-aggregates-to-alkali-silica-reac

41. Herterich J, Black L, Richardson I (2015) Microstructure and phase assemblage of low-clinker cements during early stages of carbonation. In: 14th international congress on the chemistry of cement, Beijing, China, October 13-16, 2015

Publisher's Note Springer Nature remains neutral with regard to jurisdictional claims in published maps and institutional affiliations. 